\title{
Echoes: what happens when football is played behind closed doors?
}

\author{
by J. James Reade, Dominik Schreyer \\ and Carl Singleton
}

Discussion Paper No. 2020-14

Department of Economics

University of Reading

Whiteknights

Reading

RG6 6AA

United Kingdom

www.reading.ac.uk 


\title{
Echoes: what happens when football is played behind closed doors?
}

\author{
J. James Reade \\ University of Reading
}

\author{
Dominik Schreyer \\ WHU - Otto Beisheim School of Management \\ First version: May 2020 \\ Current version: June 2020 \\ Link to latest version
}

Carl Singleton*

University of Reading

\begin{abstract}
We use a series of natural experiments in association football (soccer) to test whether the lack of social pressure from spectators affected behaviour and outcomes. We observe that the normal advantage to the home team from playing in their own stadium was on average eroded when they played behind closed doors, with no supporters. Among the various effects from no fans being present, visiting players were cautioned significantly less often by referees. This suggests that closed doors matches are different because referees favour the home team less in their decision making. We discuss these findings in the light of the Covid-19 pandemic that has led to the remainder of the 2019/20 European football season playing out in empty stadiums.
\end{abstract}

Keywords: Home Advantage, Referee Bias, Social Pressure, Attendance, Natural Experiments, Coronavirus

JEL codes: C90, D91, L83, Z20

j.j.reade@ reading.ac.uk \& c.a.singleton@reading.ac.uk (corresponding author), Department of Economics, University of Reading, Whiteknights Campus, RG6 6UA, UK. dominik.schreyer@whu.edu, Center for Sports and Management (CSM), WHU - Otto Beisheim School of Management, Erkrather Str. 224a, 40233 Düsseldorf, Germany. We would like to thank Antonio Cabrales, Marina Della Giusta, Rachel Scarfe, Daniel Schaefer, and Paul Telemo for helpful comments, as well as participants in the Reading Online Sport Seminars in March 2020. This research did not receive any specific grant from funding agencies in the public, commercial, or not-for-profit sectors 


\section{Introduction}

Social forces and pressure have the potential to affect behaviour, decision making and economic outcomes (e.g., Akerlof, 1980; Bernheim, 1994; Becker and Murphy, 2000). There is growing experimental evidence that individuals make different and potentially biased decisions in situations where there is some form of salient group membership (e.g., Charness et al., 2007; Charness and Sutter, 2012). There is evidence from real-life settings that a crowd can bias the decision making of an individual toward its preferred outcome. Specifically, home team support in a professional sports contest can impact on the officials' decisions (see the summary by Dohmen and Sauermann, 2016). In fact, fans in a football crowd believe that they do affect the outcome of a match in their own team's favour, by influencing the referee's decisions (Wolfson et al., 2005).

In this paper, we exploit a series of natural experiments in high stakes European professional football when matches had to be played in empty stadiums, to ask whether playing 'behind closed doors' disproportionately affected outcomes. Teams have typically been banned from admitting supporters into their stadiums as one-off punishments for bad behaviour off the football pitch (e.g., due to corruption, racist abuse or violence). These events provide clean breaks in the presence or not of a large crowd of spectators, which could affect the decisions made by those participating in a contest. We can also address the question of why individuals and teams perform better in specific locations, referred to as home advantage in professional sports (e.g., Schwartz and Barsky, 1977). Besides the impact of the crowd, familiarity and fatigue from travel have been proposed as explanations for why a team playing at home tends to have an increased chance of winning a contest. Since closed doors matches take place in the same venue and at the same time as they would have done if supporters were not banned, we can focus on the impact of the crowd.

We focus on 160 matches which took place behind closed doors since the beginning of the 2002/03 European season and before April 2020, comparing them with over thirty-three thousand other matches in the same competitions and period. On average, the home team won $36 \%$ of the time in empty stadiums, compared with $46 \%$ when fans were present. This was mirrored by a significant increase in the percentage of matches won by the away team in closed doors matches, accounted for by fewer goals being scored by the home teams. These patterns were common across the different competitions represented, in Italian, French and cross-border European football. However, when we account for the selection of different team qualities into these rare closed doors matches, the effect of playing without fans on home advantage is reduced and not statistically significant.

We also study whether playing football behind closed doors was associated with differences in what happened within matches. Although there was no difference in the frequency or severity of how the referee disciplined the home team, there were significant differences for the away team. With fans in the stadium, away teams were awarded on average a third of a yellow card more per match than home teams. This difference was generally cancelled out when teams played behind closed doors, with up to 0.8 fewer yellow cards awarded to the away team in the elite Serie A and French 
Ligue 1 competitions. This estimated effect, also large and significant in Italian football overall and in the full sample of matches, was robust to the assignments of different teams and referees, as well as reasonable variations on the preferred specification of the regression model. These results suggest that the complete absence of a crowd in a football match eliminates the bias against the away team in punishments, normally caused by social pressure from the mostly home team supporting fans. This is broadly consistent with a study by Pettersson-Lidbom and Priks (2010) (henceforth PLP) of 21 Italian closed doors matches in 2006/07, which also feature in our sample. We extend this previous study by increasing the sample size considerably, by addressing the selection of participant characteristics into the matches played without fans, and by looking at other outcomes besides team discipline. Like PLP, we find further support for the conclusion that a crowd affects football matches through the referee, by showing that some features of game play were not significantly different when a match was played behind closed doors, such as ball possession and the rate of shots on goal being on target.

These results are particularly relevant at the present time, as global professional sport has largely had to take place behind closed doors since the beginning of the Covid-19 pandemic. For a highly infectious and destructive airborne virus, common sense suggests that playing in empty stadiums could become the new normal for sports. Not only that, but there is evidence that the transmission of influenza can be significantly increased by the public gatherings surrounding major sports events (Stoecker et al., 2016; Cardazzi et al., 2020). There is also preliminary evidence that professional sports can explain some of the regional variation in US deaths during the early Covid-19 outbreak (Ahammer et al., 2020).

We proceed as follows: in section 2, we discuss some related literature; in section 3, we describe our dataset of football matches and provide some descriptive information (e.g., regarding match outcomes); in section 4, we present both our estimation strategy and the main results; in section 5, we reflect on what has happened to home advantage in European professional football since the Covid-19 lockdowns began; and in section 6, we offer some concluding remarks.

\section{Related literature}

This paper contributes to a large literature describing or seeking to explain the causes of home advantage in professional sports. This tendency of a team to win more often when playing in their home stadium, city or country has been prevalent throughout the history of professional team sports in North America and Europe (e.g., Courneya and Carron, 1992; Nevill and Holder, 1999; Pollard and Pollard, 2005). In an early study, Schwartz and Barsky (1977) pointed toward greater home advantage within indoor sports, such as basketball and ice hockey, than outdoor, finding that the support of the home crowd was a major factor. In the English Football League, since its founding in 1888, for a long time there were only small variations in home advantage between seasons (Pollard, 1986), but in recent decades there has been a persistent and substantial decline in home advantage, that otherwise exists independently of the large cross-league differences in 
stadium attendances (Koyama and Reade, 2009; Peeters and van Ours, 2020). ${ }^{1}$ This has led to the suggestion that crowd size may not play a substantial role in football, and instead familiarity with home conditions could be a more important factor. Although Boyko et al. (2007) found some evidence that home advantage in English football may relate to the crowd and its influence on referees, this was contradicted by Johnston (2008) in a replication study using more recent data. Clarke and Norman (1995) identified the home advantage of different English football teams over time, finding that this appeared to be lower for teams clustered in London. They reasoned that this could be due to fatigue as London-based teams' opponents had to travel less to play them. There is also some suggestion that home advantage could be caused by the territoriality of players, based on monitoring their testosterone levels before matches (Neave and Wolfson, 2003).

Recent studies have sought to shed new light on the question of what drives home advantage by exploiting specific features of leagues and the scheduling of matches. Ponzo and Scoppa (2018) studied football matches in Italy where teams shared the same home stadium, ruling out differences in travel fatigue and familiarity. They found sizeable effects of crowd support on home advantage. In a similar study of two basketball teams who share a stadium in Los Angeles, Boudreaux et al. (2017) found large attendance effects on the home team's performance. Goller and Krumer (2020) studied four of the major European football leagues and found that matches scheduled on non-frequently played days tended to have both lower attendances and less home advantage. However, Belchior (2020) studied the quasi-random reassignment of matches in Brazilian football to time slots which generally increased attendances, finding that this had no effect on home advantage.

This paper also contributes to past studies which have focused on the bias of sports officials, and how this interacts with social pressure from the crowd. In an experimental setting using qualified English referees, Nevill et al. (2002) found that background noise significantly affected judgements of what constituted foul play, with decisions becoming less certain and increased bias toward the home team. Garicano et al. (2005) and Sutter and Kocher (2004) identified a systematic bias among referees in the top levels of Spanish and German football, respectively. In particular, they found that referees behave as if to satisfy the home crowd, by systematically shortening matches when the home team is winning and lengthening them when the home team is losing. Garicano et al. (2005) also used variation in crowd size and composition to suggest that social pressure is the cause of referee bias. Similar effects of the crowd on referee bias in injury time decisions were documented by Dohmen (2008a) for German football and Scoppa (2008) for Italian football. Rocha et al. (2013) showed that this source of referee bias is more prevalent in Brazilian football when matches are televised. Studying punishments for foul play, Dawson et al. (2007) found that home teams tend to accumulate fewer red and yellows cards than away teams, with this not relating to home advantage but instead appearing to be driven by referee bias. Extending this analysis to international football, Dawson and Dobson (2010) identified the nationality of referees as another important factor affecting their favouritism toward one team or another. Buraimo et al. (2010) and Buraimo et al. (2012) found

\footnotetext{
${ }^{1}$ See the left-hand panel of Figure 5 for a graphical representation of this long decline across football in 105 countries and geographical areas, a trend that appears to begin after the Second World War.
} 
further convincing evidence that social pressure affects the punishment decisions of referees, by accounting for the specific patterns of play within English, German and Spanish top league matches. In addition, they found that the presence of a running track in the stadium, increasing the distance between the fans and the referee, tended to reduce the bias against the away team. But Goumas (2014) found that a crowd's density was the most important factor in European football, rather than its size or proximity to the pitch. Looking at heterogeneity among referees, Page and Page (2010) showed that some referees are more susceptible to being influenced by a crowd than others. Finally, as an example away from football, Sacheti et al. (2015) studied the home bias of international cricket umpires, exploiting rule changes governing whether they could share the same nationality as teams playing. They found that these natural experiments decreased the bias toward the home team in important umpiring decisions within games, with the reduction in social pressure from the home crowd on home-based umpires being the probable cause.

\section{Data}

In our analysis, we explore all football matches since the beginning of the 2002/03 European season in the following seven competitions: (1) UEFA Champions League, (2) UEFA Europa League, (3) French Ligue 1, (4) Italian Serie A, (5) Italian Serie B, (6) Italian Serie C, and (7) Coppa Italia, the major Italian domestic cup competition. ${ }^{2}$ As such, our rich data set contains a heterogeneous mix of matches, played in both domestic and European cup competition and involving teams with a range of abilities.

We considered looking at a longer time period, i.e., since the end of WW2, but we found that football matches taking place behind closed doors in the major European professional football competitions were sporadic before 2002. In fact, to the best of our knowledge, the last game prior to 2002 in these competitions that took place without fans was in 1993 in Italy. Also, we ignore the other three of the top five European football leagues, in England, in Germany and in Spain, because there were only two matches in these competitions since 2002 and before April 2020 without fans.

We exclude all matches since the Covid-19 shutdown from the main analysis here because the absence of the fans is not the only thing that has changed. Rules have been temporarily altered to facilitate the completion of the 2019/20 domestic seasons in less time than was planned, such as on the number and timing of player substitutions within matches. Further, we would not be able to rule out that the virus itself or the break from training and competition that it caused have affected match outcomes. Despite not using matches since the Covid-19 shutdown in the main analysis because of the above facts, in Section 5, we document how home advantage, at least on the surface, appears to have been substantially reduced across the leagues that have returned to action since May 2020.

In Figure 1, we show the distribution of the studied closed doors matches over competitions and seasons. We define three partly overlapping sub-groups of matches: (1) continental football in

\footnotetext{
${ }^{2}$ Excludes the qualifying stages of the UEFA competitions, but the Coppa Italia is included from round 1 onward.
} 
the UEFA competitions, (2) domestic football in Italy, and (3) what we call Elite football, which comprises of the top leagues in France and Italy, Ligue 1 and Serie A. There were just 160 matches that had no fans present since 2002, out of a total of 33,796 matches, excluding those that took place in neutral stadiums, such as the UEFA competition finals. As one can see from Figure 1, around $40 \%$ of the closed doors matches took place in just two seasons, 2006/07 and 2019/20. Italy accounted for most of these matches. The first cluster of games without fans followed from the Italian Calciopoli scandal, which was previously studied by PLP. The second cluster of games took place in 2020, just before the the Covid-19 virus lockdowns and bans on professional sports. As such, Italian football dominates our sample of closed doors matches, but almost a quarter took place in the UEFA competitions, and there were nineteen in the French Ligue 1.

FIGURE 1: Sample number of closed doors matches by season and competition/country

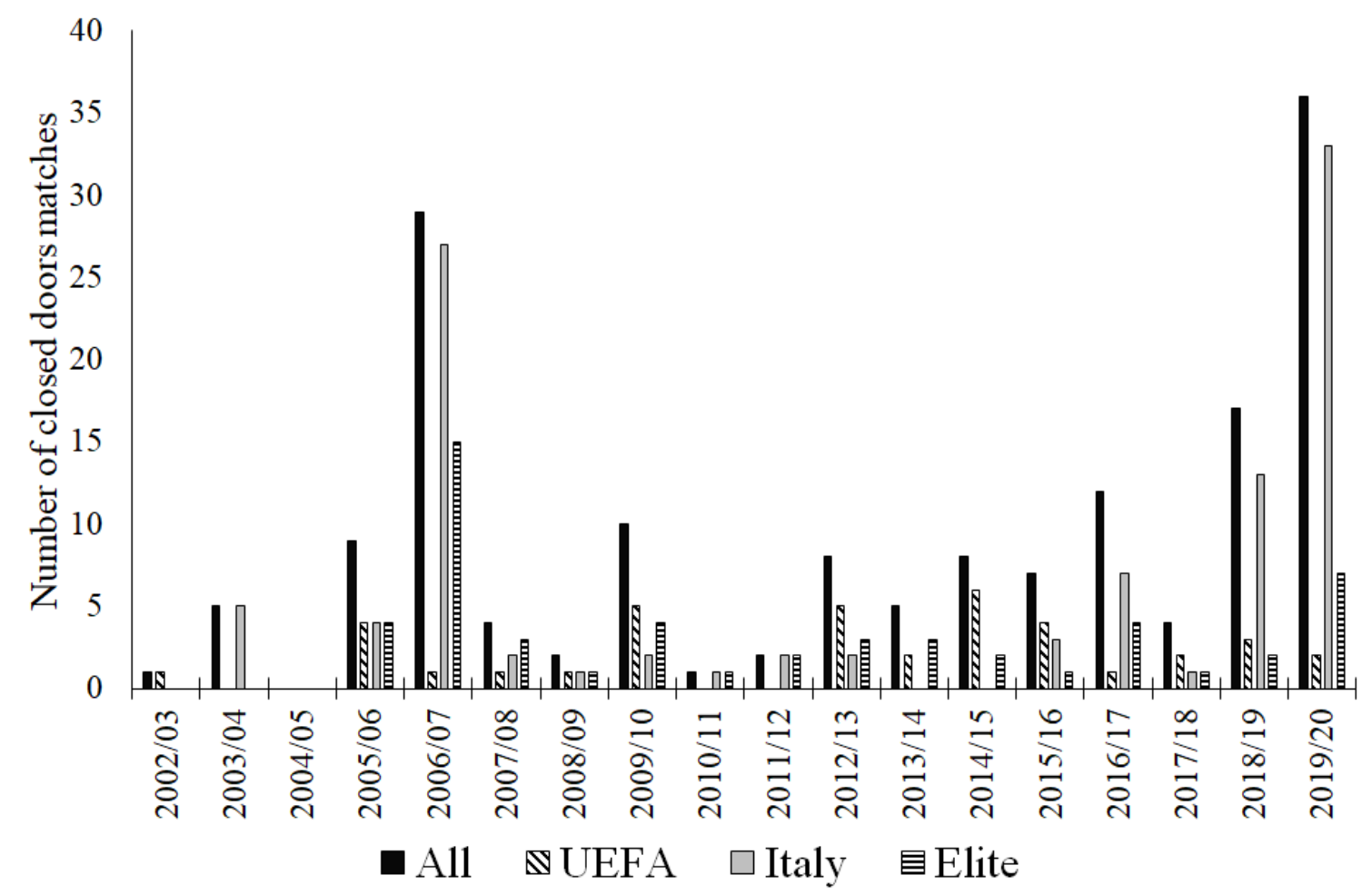

Notes.- "All" refers to all competitions in the sample. "UEFA" refers to matches in the UEFA Champions League, Europa League and their previous iterations under different names. "Italy" refers to matches in Seria A, Serie B, Serie $\mathrm{C}$ and Coppa Italia. "Elite" refers to the French Ligue 1 and the Italian Serie A. Source.- worldfootball.net; accessed 14 March 2020.

We collect data on what happened within these football matches and their final outcomes from two data sources: (1) worldfootball.net and (2) espn.co.uk/football. The first of these sources is the most important. In Tables 1 \& 2, we present descriptive statistics over all 33,796 matches, as well as the 5,684, 21,377 and 13,301 matches in the UEFA, Italy and Elite sub-samples, respectively. The data represent 458 different teams playing at home and 581 different teams playing away from home. They correspond to 13,993 distinct match ups between specific home and away teams, e.g., 
Juventus F.C. playing at home in Turin against A.C. Milan. ${ }^{3}$ We also know the identity of the 701 different referees who officiated these matches. In Table 1, we show that attendances in professional European football were quite variable in this period, ranging from zero in matches played behind closed doors to a maximum of 98,800. Attendances were on average higher and more variable in the UEFA competitions than the domestic leagues, though the Elite matches still had a respectable median attendance of 18,200. The matches studied in Italy typically had lower attendances than the rest of the sample, because the lower leagues and Coppa Italia generally attracted fewer fans.

In Table 1, we also summarise the Elo (1978) ratings of the home and away teams represented in the study. These are time-varying measures of each team's relative strengths, and are a function of the entire history of European domestic and continental professional football result outcomes scraped from worldfootball.net. They also capture the recent form of teams, as the recursive updating of the ratings after each match weights those completed recently more highly. ${ }^{4}$ The Elo ratings will be useful control variables in the following regression analysis. Elo ratings were typically lower in the Italian domestic sub-sample, and they were on average higher in the Elite leagues than in the UEFA competitions. The latter involved teams from countries with weaker domestic leagues than in Italy and France.

It is well-known that home advantage is substantial in professional football. In Table 2, we show that in all the matches considered here since 2002, 46\% ended in a home win, $28 \%$ in a draw and $26 \%$ in an away win. The home advantage has tended to be greater in the UEFA competitions than in domestic football and was marginally greater at the Elite level than in Italy overall, when including the lower-league teams. These patterns across the competitions were also reflected in the average goal difference between the home and away teams, which was 0.4 goals in the whole sample and had a median value in all the competitions of zero.

When a referee determines that there has been foul play in a football match, in addition to awarding a free-kick to the team that was fouled, there are three more serious ways that he can decide to punish players and teams. First, he/she can award a yellow card to a player, also know as a caution. Cumulative yellow cards over matches can result in players becoming suspended. If a player is awarded two yellow cards in the same match, then he/she is excluded from the remainder of the match, meaning that their team must finish the match at a significant disadvantage to the opponent, with one player fewer. Second, the referee can award a straight red card to a player for serious foul play, resulting in a direct exclusion. Third, if a foul is committed by a team in their own penalty area, then the referee will award a penalty kick to the opposing team. A penalty is a significant punishment in football, since the game is generally low-scoring and it results in a goal

\footnotetext{
${ }^{3}$ We discard and never describe all matches where the team playing at home only appeared once in the respective sub-group in a season, because in the regression analysis that follows we at least account for home-team-season fixed effects. For example, if an Italian Serie D team lost at home in the first round of the Coppa Italia, then that match would be discarded.

${ }^{4}$ Elo ratings, originally proposed by Elo (1978) for chess players and tournaments, are commonly used to estimate the strengths and form of football teams, both in practical applications (e.g., https://www.eloratings.net/) and in academic research (e.g., Hvattum and Arntzen, 2010).
} 
TABLE 1: Summary statistics over football matches (Part I), 2002/03-2019/20

\begin{tabular}{|c|c|c|c|c|c|}
\hline & Mean & St. Dev. & Min. & Median & Max. \\
\hline \multicolumn{6}{|l|}{$A l l$} \\
\hline Attendance (1000s) & 16.0 & 15.9 & 0.0 & 11.1 & 98.8 \\
\hline Home Elo rating & 1085 & 107 & 732 & 1076 & 1532 \\
\hline Away Elo rating & 1079 & 107 & 741 & 1069 & 1517 \\
\hline$N$ of home teams & & & 458 & & \\
\hline$N$ of away teams & & & 581 & & \\
\hline$N$ of home-away team pairs & & & 13,993 & & \\
\hline$N$ of referees & & & 701 & & \\
\hline$N$ of matches & & & 33,796 & & \\
\hline$N$ behind closed doors & & & 160 & & \\
\hline \multicolumn{6}{|c|}{ European Competition (UEFA) } \\
\hline Attendance (1000s) & 29.8 & 19.5 & 0.0 & 25.5 & 98.8 \\
\hline Home Elo rating & 1095 & 100 & 835 & 1090 & 1524 \\
\hline Away Elo rating & 1096 & 101 & 836 & 1089 & 1510 \\
\hline$N$ of home teams & & & 284 & & \\
\hline$N$ of away teams & & & 375 & & \\
\hline$N$ of home-away team pairs & & & 4,767 & & \\
\hline$N$ of referees & & & 392 & & \\
\hline$N$ of matches & & & 5,684 & & \\
\hline$N$ behind closed doors & & & 38 & & \\
\hline \multicolumn{6}{|l|}{ Italy } \\
\hline Attendance (1000s) & 10.8 & 12.8 & 0.0 & 6.0 & 81.8 \\
\hline Home Elo rating & 1074 & 111 & 732 & 1064 & 1532 \\
\hline Away Elo rating & 1066 & 111 & 740 & 1055 & 1517 \\
\hline$N$ of home teams & & & 171 & & \\
\hline$N$ of away teams & & & 204 & & \\
\hline$N$ of home-away team pairs & & & 7,962 & & \\
\hline$N$ of referees & & & 296 & & \\
\hline$N$ of matches & & & 21,377 & & \\
\hline$N$ behind closed doors & & & 103 & & \\
\hline \multicolumn{6}{|l|}{ Serie A \& Ligue 1 (Elite) } \\
\hline Attendance (1000s) & 22.3 & 13.7 & 0.0 & 18.2 & 81.8 \\
\hline Home Elo rating & 1135 & 107 & 824 & 1122 & 1532 \\
\hline Away Elo rating & 1130 & 106 & 860 & 1114 & 1517 \\
\hline$N$ of home teams & & & 85 & & \\
\hline$N$ of away teams & & & 85 & & \\
\hline$N$ of home-away team pairs & & & 2,650 & & \\
\hline$N$ of referees & & & 191 & & \\
\hline$N$ of matches & & & 13,301 & & \\
\hline$N$ behind closed doors & & & 53 & & \\
\hline
\end{tabular}

Notes.- statistics are calculated over all matches in the analysis sample since the beginning of the 2002/03 season. Excludes matches where the home team appeared only once in a competition in a given season. Source.worldfootball.net; accessed 14 March 2020. 
TABLE 2: Summary statistics over football matches (Part II), 2002/03-2019/20

\begin{tabular}{|c|c|c|c|c|c|}
\hline & Mean & St. Dev. & Min. & Median & Max. \\
\hline \multicolumn{6}{|l|}{$A l l$} \\
\hline Home win (\%) & 45.8 & & & & \\
\hline Draw $(\%)$ & 28.2 & & & & \\
\hline Away win $(\%)$ & 26.0 & & & & \\
\hline Goal diff. (Home-Away) & 0.40 & 1.62 & -9 & 0 & 15 \\
\hline Yellow cards & 4.21 & 1.98 & 0 & 4 & 13 \\
\hline Red cards & 0.29 & 0.57 & 0 & 0 & 5 \\
\hline Penalty kicks & 0.19 & 0.45 & 0 & 0 & 5 \\
\hline Penalties missed (\%) & 21 & 40 & 0 & 0 & 100 \\
\hline \multicolumn{6}{|c|}{ European Competition (UEFA) } \\
\hline Home win $(\%)$ & 49.2 & & & & \\
\hline Draw $(\%)$ & 23.9 & & & & \\
\hline Away win $(\%)$ & 26.9 & & & & \\
\hline Goal diff. (Home-Away) & 0.51 & 1.85 & -7 & 0 & 8 \\
\hline Yellow cards & 3.83 & 2.07 & 0 & 4 & 12 \\
\hline Red cards & 0.20 & 0.47 & 0 & 0 & 3 \\
\hline Penalty kicks & 0.18 & 0.45 & 0 & 0 & 5 \\
\hline Penalties missed (\%) & 31 & 45 & 0 & 0 & 100 \\
\hline \multicolumn{6}{|l|}{ Italy } \\
\hline Home win $(\%)$ & 44.9 & & & & \\
\hline Draw $(\%)$ & 29.3 & & & & \\
\hline Away win $(\%)$ & 25.8 & & & & \\
\hline Goal diff. (Home-Away) & 0.37 & 1.54 & -7 & 0 & 15 \\
\hline Yellow cards & 4.50 & 1.94 & 0 & 4 & 13 \\
\hline Red cards & 0.33 & 0.60 & 0 & 0 & 5 \\
\hline Penalty kicks & 0.20 & 0.46 & 0 & 0 & 5 \\
\hline Penalties missed & 18 & 37 & 0 & 0 & 100 \\
\hline \multicolumn{6}{|l|}{ Serie A \& Ligue 1 (Elite) } \\
\hline Home win $(\%)$ & 45.7 & & & & \\
\hline Draw $(\%)$ & 27.8 & & & & \\
\hline Away win $(\%)$ & 26.6 & & & & \\
\hline Goal diff. (Home-Away) & 0.39 & 1.63 & -9 & 0 & 9 \\
\hline Yellow cards & 4.07 & 1.95 & 0 & 4 & 11 \\
\hline Red cards & 0.27 & 0.55 & 0 & 0 & 5 \\
\hline Penalty kicks & 0.19 & 0.45 & 0 & 0 & 5 \\
\hline Penalties missed & 24 & 42 & 0 & 0 & 100 \\
\hline
\end{tabular}

Notes.- see also Table 1. Source.- worldfootball.net; accessed 14 March 2020. 
more often than not. ${ }^{5}$ In Table 2, we show sample statistics for these three punishments. On average, 4.2 yellow cards were awarded per match, with more cards in Italy than in the continental football. The standard deviation of yellow cards per match was around two. Depending on the competition, a red card, both straight and via two yellows, was awarded every three to five matches, being rarer in the UEFA competitions than in domestic football. On average, a penalty was awarded in around one in five matches. These penalties were missed (i.e., not scored) substantially more often in the UEFA matches $(31 \%)$ than in Italy (18\%) and at the Elite domestic level (24\%).

For a sub-sample of the matches described in Tables $1 \& 2$, namely most of those in the UEFA and Elite sub-samples, we have information on other match features from espn.co.uk/football: the numbers of fouls committed; injury time awarded by the referee toward the end of the first and second halfs, along with the match scoreline at the time; the share of ball possession by the home team; total shots on goal by each team, including the numbers on target; and the numbers of saves made by goalkeepers. In the next section, we describe whether professional football with or without fans is associated with differences in all these match features, along with the main outcomes that we described in Tables $1 \& 2$.

\section{Estimation \& main results}

The ideal experiment to test the impacts of playing football without fans would involve repeating the same matches many times, with the same players, officials and conditions, only varying whether or not spectators were allowed into the stadium. But this is impractical, and so we apply panel data regression methods to the historical sample of matches described above, to get as close as possible to the ideal experiment.

With some small variations, for each outcome, $y_{i}$, in match $i$, we estimate the following using least squares:

$$
y_{i}=\alpha+\lambda \text { ClosedDoors }_{i}+\beta_{1} \text { Attendance }_{i}+\beta_{2} \text { HomeElo }_{i}+\beta_{3} \text { AwayElo }_{i}+\varepsilon_{i} .
$$

The regression models all include a constant, $\alpha$, and controls for the time-varying strengths and form of both the home and away teams, via Elo ratings with coefficients $\beta_{2}$ and $\beta_{3}$. For robustness, we allow different structures for the error term, $\varepsilon_{i}$. In our preferred specification, this includes fixed effects for both the home-team-season, $\psi_{H S(i)}$ and the away-team-season, $\psi_{A S(i)}$, where $H S(i)$ and $A S(i)$ are functions indicating that match $i$ took place in season $s$ and involved home team $h$ or away team $a$ :

$$
\varepsilon_{i}=\psi_{H S(i)}+\psi_{A S(i)}+\eta_{i}
$$

\footnotetext{
${ }^{5}$ With this in mind, when an apparent foul in the penalty area isn't awarded by the referee, it is often said by football match commentators and fans: "if that were anywhere else on the pitch, then it would have been a foul", i.e., the implications of awarding a penalty kick suggestively make the referee think twice about awarding a foul. The same is also often said about a referee's decision to award a second yellow card for foul play or not, i.e., the necessary severity of a foul to warrant a second yellow is typically higher.
} 
where the remaining heterogeneity is in the residual, $\eta_{i}$. In this case, $\beta_{1}$ estimates the effect on each outcome of a change in the number of spectators within a home team's season, conditional on who the visiting team was. ClosedDoors ${ }_{i}$ is a dummy variable taking the value one if a match was played behind closed doors. The associated coefficient, $\lambda$, estimates the disproportionate impacts on the outcomes of a match from playing behind closed doors, with no fans present at all. This is what we focus on in the results, as it could suggest that playing without fans matters far more than the typically small or insignificant effects of regular variation in match attendances accounted for by the linear $\beta_{1}$ Attendance $_{i}$ term. $^{6}$

We also estimate Equation (1) with match-up fixed effects: $\varepsilon_{i}=\psi_{M(i)}+\eta_{i}$, where $M(i)$ indicates that $i$ was a match up, $m$, between specific home and away teams. Since each match up typically occurs once per season, the effect of playing behind closed doors is then identified within matches that were similar besides the presence or not of fans, but over a long period of time. We prefer estimates that instead address team-season level heterogeneity, as these better address the fact that teams change over time, especially between seasons, through changes in the players, managers, tactics and fans. This is also akin to how home advantage in sports league is normally estimated (e.g., Clarke and Norman, 1995). We also check whether our results are robust to the assignment of different referees over matches by the inclusion in Equation (1) of referee fixed effects, $\psi_{R(i)}$. It is plausible that some referees tend to impart stricter discipline or greater home advantage than others. Given the relatively small number of closed doors matches in the sample, it is important that we check whether referee heterogeneity drives any of the results.

Despite the fact that the final outcomes of football matches are ordinal, e.g., win, draw or lose, and counts of goals, we prefer to estimate the linear regression model given by Equation (1) rather than, for example, an ordered latent variable model or a Poisson count model. This is justified because we are focused on the average marginal effects of playing a match behind closed doors, and the models also control for a lot of unobserved heterogeneity with the different sets of fixed effects (Wooldridge, 2010). Besides, the linear regression model, with its easy implementation and interpretation, is preferable to selecting some potentially wrong non-linear model. ${ }^{7}$ To address heteroskedasticity in the residuals, we generally estimate standard errors that are clustered at the level of the home-team-season, reasoning that some outcomes may have been more or less variable within particular stadiums and seasons, and because the sample selects particular stadium-seasons in European professional football from the overall historical population of football matches. When the outcome relates more to the actions of the away team players, e.g., yellow cards awarded to the away team or the percentage of shots on target, we instead cluster standard errors at the away-team-season level.

\footnotetext{
${ }^{6} \mathrm{We}$ considered the inclusion of squared attendance and ELO ratings in the regression models. These terms were typically insignificant and the estimated marginal effects of closed doors matches were robust to their inclusion. These results are available on request.

${ }^{7}$ To assuage doubts about our preference for the more tractable linear regression model, we estimate non-linear equivalents for some match outcomes, such as the ordered probit model for the final results of matches. The marginal effects of playing football behind closed doors were robust to this regression model choice. Some Poisson regression results are presented below and other results are available on request.
} 


\subsection{Final match outcomes and home advantage}

Before estimating any regression models, in Table 3 and the first seven statistics in Figure 2, we compare the sample means of final outcomes in matches played with fans and without. In the top panel of Table 1, we pool all matches, whereas in the three panels below we focus on the UEFA, Italy and Elite sub-samples, as described in Section 3. Of the 160 closed doors matches, $35.6 \%$ were won by the team playing at home, 10.2 percentage points less than in matches with fans ( $p$-value $<$ 0.01 ). Mirroring this, the away team was 7.8 percentage points more likely to have won in the sample of closed doors matches than when fans were present ( $p$-value $<0.05)$. These patterns are replicated in the three smaller sub-samples, though the difference between the two types of matches was only statistically significant in the UEFA competitions, where closed doors matches were on average 20.4 percentage points less likely to end in a home win than with fans ( $p$-value $<0.05$ ). The lower mean goal difference between teams of 0.30 when matches were played behind closed doors ( $p$-value $<0.05$ ) also implies less home advantage. There was no significant difference between with and without fans in the mean total goals scored in a match, suggesting that the presence of fans was not related to more attacking play, only reduced home advantage.

FIGURE 2: Differences in sample means of football match outcomes: closed doors vs with fans, 2002/03-2019/20

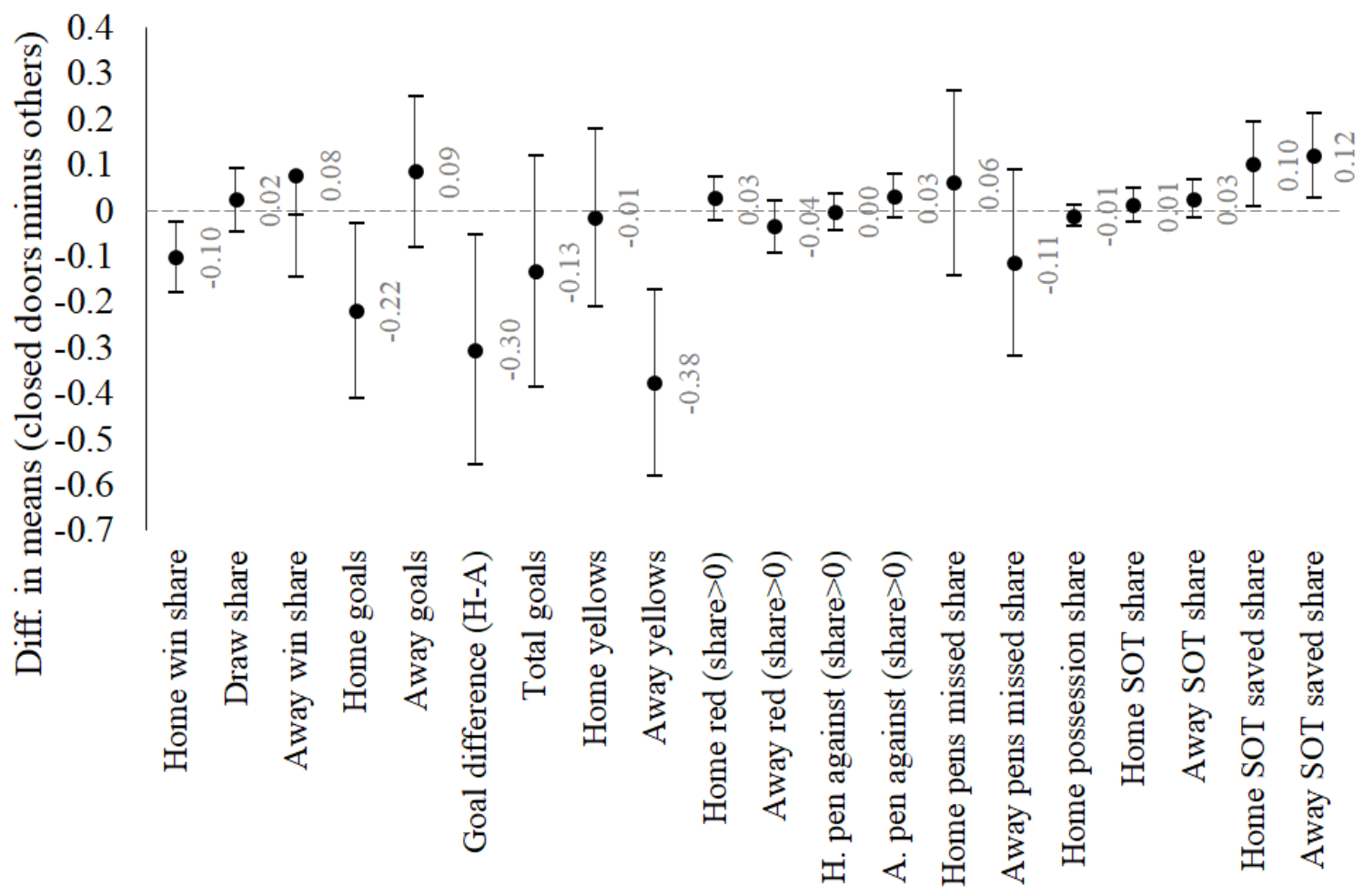

Notes.- Uses all matches in the UEFA Champions League, Europa League, Italian Serie A, Serie B, Serie C, Coppa Italia and French Ligue 1 since the beginning of the 2002/03 season. See Figure 1 and Tables 1-2 for further sample description. 95\% confidence intervals displayed. Source.- author calculations using worldfootball.net and espn.co.uk/football; accessed 14 March 2020. 
TABLE 3: Comparison of sample means for final outcomes between matches with fans and without, 2002/03-2019/20

\begin{tabular}{|c|c|c|c|}
\hline & $\begin{array}{l}\text { With fans } \\
\text { (I) }\end{array}$ & $\begin{array}{l}\text { Closed doors } \\
\text { (II) }\end{array}$ & $\begin{array}{l}\text { Diff. } \\
\text { (III) }\end{array}$ \\
\hline \multicolumn{4}{|l|}{ All } \\
\hline Home win $(\%)$ & 45.8 & 35.6 & $10.2^{* *}$ \\
\hline Draw $(\%)$ & 28.2 & 30.6 & -2.4 \\
\hline Away win (\%) & 25.9 & 33.8 & $-7.8^{*}$ \\
\hline Home goals & 1.45 & 1.23 & $0.22^{*}$ \\
\hline Away goals & 1.05 & 1.14 & -0.09 \\
\hline Goal diff. & 0.40 & 0.09 & $0.30^{*}$ \\
\hline Total goals & 2.50 & 2.37 & 0.13 \\
\hline \multicolumn{4}{|c|}{ European Competition (UEFA) } \\
\hline Home win $(\%)$ & 49.3 & 28.9 & $20.4^{*}$ \\
\hline Draw $(\%)$ & 23.9 & 28.9 & -5.1 \\
\hline Away win (\%) & 26.8 & 42.1 & $-15.3^{*}$ \\
\hline Home goals & 1.61 & 1,39 & 0.22 \\
\hline Away goals & 1.10 & 1.37 & -0.27 \\
\hline Goal diff. & 0.51 & 0.03 & 0.48 \\
\hline Total goals & 2.71 & 2.76 & -0.05 \\
\hline \multicolumn{4}{|l|}{ Italy } \\
\hline Home win (\%) & 45.0 & 36.9 & 8.1 \\
\hline Draw $(\%)$ & 29.3 & 33.0 & -3.7 \\
\hline Away win (\%) & 25.7 & 30.1 & -4.4 \\
\hline Home goals & 1.42 & 1.21 & 0.21 \\
\hline Away goals & 1.05 & 1.09 & -0.03 \\
\hline Goal diff. & 0.37 & 0.13 & 0.24 \\
\hline Total goals & 2.47 & 2.30 & 0.17 \\
\hline \multicolumn{4}{|c|}{ Serie A \& Ligue 1 (Elite) } \\
\hline Home win (\%) & 45.7 & 39.6 & 6.1 \\
\hline Draw $(\%)$ & 27.8 & 28.3 & -0.5 \\
\hline Away win (\%) & 26.5 & 32.1 & -5.5 \\
\hline Home goals & 1.45 & 1.21 & 0.25 \\
\hline Away goals & 1.06 & 1.15 & -0.08 \\
\hline Goal diff. & 0.39 & 0.06 & 0.33 \\
\hline Total goals & 2.52 & 2.36 & 0.16 \\
\hline
\end{tabular}

Notes.- $* * * * * *$ indicate significant differences in means between matches with fans and without at $0.1 \%, 1 \%$ and $5 \%$ levels, respectively, two-sided $t$-tests. See Table 1 for Ns. Source.- author calculations using worldfootball.net; accessed 14 March 2020. 
In the top panel of Table 4, we show linear probability model (LPM) estimates of the disproportionate impact of playing matches behind closed doors on whether the home team wins, draws or loses, i.e., $\widehat{\lambda}$ in Equation (1). In column (I), we show results for the pooled sample of matches, and in columns (II)-(IV) we focus on the UEFA, Italy and Elite sub-samples. For the sake of brevity throughout the remainder of the paper, for each regression model we do not describe the coefficient estimates for the ELO rating and linear attendance control variables, instead focusing only on the marginal effect of a closed doors match. ${ }^{8}$ In row 1 , we display significant negative impacts of playing without fans on the probability of a home win when only controlling for home-team-season fixed effects. But when we also control for away-team-season heterogeneity in row 2, the impact of playing behind closed doors on home advantage is reduced and not statistically significant from zero at standard levels. Although, the marginal effect is nonetheless large, with an implied decrease in the probability of a home win of around 0.05 when there are no fans.

In row 3 of Table 4, we identify the impact of playing behind closed doors within specific match-ups. In this case, home advantage is significantly decreased when fans are not present, with a reduction in the home win probability in the pooled sample of matches of 0.13 ( $p$-value $<0.01$ ). However, we prefer the estimates in row 2, because they control for the different strengths of the teams playing either at home or away, across different seasons. In other words, these estimates are robust to the possibility that closed doors matches may have tended to involve weak home teams and strong away teams. This tendency does appear to account for most of the reduced home advantage in matches played without fans that we described in the sample means in Table 3. In row 4, when we restrict the estimation samples to home-team-seasons that actually featured a closed doors match, i.e., just 1,884 matches in the pooled sample, the effect of playing without fans on the final result remains statistically insignificant.

In the lower panel of Table 4, we estimate the preferred regression model specification as per row 2 but vary the dependent variable. In rows 5-8, we show that there are generally no significant effects of playing behind closed doors on goal difference and the numbers of goals scored by the home team, the away team or in total. This is the case not only for the whole sample but also for the three sub-samples. The magnitudes of some of the estimated marginal effects are large, such as the 0.27 reduction in home goals scored both in Italy and at the Elite level in empty stadiums ( $p$-value $<0.1$ ). But the small number of closed doors matches available to us, coupled with the general unpredictability of football, means that these estimates struggle to pass standard levels of statistical significance.

\footnotetext{
${ }^{8}$ The coefficient estimates on these control variables are generally small, and not especially interesting, being consistent with the broader literature. For example, in \{row 1, column (I) \} of Table 4, the estimated effect of an additional 1,000 fans in the stadium is to decrease the probability of a home win by 0.003 ( $p$-value $<0.001$ ), because stronger opponents attract more fans. But this effect goes toward zero and is statistically insignificant when we add away-team-season fixed effects to the regression model, i.e., \{row 2, column (I) $\}$ of Table 4.
} 
TABLE 4: Regression model estimates of the effect of playing matches behind closed doors on final outcomes, 2002/03-2019/20

\begin{tabular}{lllll}
\hline & $\begin{array}{l}\text { All } \\
\text { (I) }\end{array}$ & $\begin{array}{l}\text { UEFA } \\
\text { (II) }\end{array}$ & $\begin{array}{l}\text { Italy } \\
\text { (III) }\end{array}$ & $\begin{array}{l}\text { Elite } \\
\text { (IV) }\end{array}$ \\
\hline Match result & & & & \\
1. Home-season FEs & $-0.141^{* * *}$ & $-0.265^{* *}$ & $-0.097^{*}$ & $-0.148^{*}$ \\
& $(0.04)$ & $(0.08)$ & $(0.04)$ & $(0.07)$ \\
2. + away-season FEs & -0.054 & -0.058 & -0.041 & -0.037 \\
& $(0.04)$ & $(0.12)$ & $(0.05)$ & $(0.06)$ \\
3. Match-up FEs & $-0.131^{* *}$ & & $-0.121^{*}$ & $-0.151^{*}$ \\
& $(0.04)$ & & $(0.05)$ & $(0.07)$ \\
4. Reduced sample & -0.063 & & -0.053 & 0.043 \\
& $(0.07)$ & & $(0.06)$ & $(0.10)$ \\
Goals scored & & & & \\
5. Home & -0.203 & 0.363 & $-0.265^{*}$ & -0.265 \\
& $(0.11)$ & $(0.42)$ & $(0.13)$ & $(0.14)$ \\
6. Away & -0.093 & -0.088 & -0.108 & -0.132 \\
& $(0.10)$ & $(0.32)$ & $(0.12)$ & $(0.19)$ \\
7. Goal diff. & -0.110 & 0.451 & -0.156 & -0.134 \\
8. Total & $(0.15)$ & $(0.51)$ & $(0.17)$ & $(0.21)$ \\
& -0.294 & 0.294 & -0.339 & -0.397 \\
\hline
\end{tabular}

Notes.- $* * * * * *$ indicate significance from zero at $0.1 \%, 1 \%$ and $5 \%$ levels, respectively, two-sided tests, home-team-season cluster robust standard errors are displayed in parentheses. All regression models should be interpreted as linear (probability) models, unless stated otherwise (see Equation (1)). All models include as control variables: home team Elo rating, away team Elo rating and match attendance. 1. $\{$ Home,Draw, Away $\}=\{1,0.5,0\}$, home-team-season fixed effects included only; 2. adds away-team-season fixed effects to 1; 3. home-team-away-team (match-up or fixture) fixed effects instead; 4. equiv. to 2. but reduced sample (see text); 5 . equiv. to 2 . but the outcome is the number of home goals scored; 6 . equiv. to 2 . but the outcome is the number of away goals scored; 7 . equiv. to 2 . but the outcome is the goal difference (home - away); 8 . equiv. to 2 . but the outcome is the total goals scored (home + away). Source.- author calculations using worldfootball.net; accessed 14 March 2020. 


\subsection{Discipline and foul play}

In Table 5 and the middle part of Figure 2, we compare the sample means of the different punishments that referees can hand out, between matches with fans and without. Column (I) shows that when spectators were present, referees awarded around 0.4 more yellow cards to players on the away team than on the home team. This was consistent across all the competitions studied here. Likewise, the proportions of matches where the away team was awarded at least one red card or where they gave away at least one penalty were higher than for the home team. These differences are why previous studies have suggested that referee bias toward the home team may account for at least some of the home advantage in football (e.g., Dohmen, 2008b; Dohmen and Sauermann, 2016), though it has proven impossible to completely rule out that the nature of play by teams could also explain these differences in punishments. We find that on average there was no statistically significant difference between matches with fans and without in the mean number of yellow cards awarded to home team players. Likewise, playing behind closed doors was not associated with any significant differences in how likely a given match was to feature a red card or a penalty for either the home or away teams. But on average, 0.4 fewer cards per match were awarded to the away team in empty stadiums ( $p$-value $<0.001$ ), effectively cancelling out the mean difference in yellow cards between teams when fans were present. This pattern is replicated in the three sub-samples, though not significantly so in the UEFA competitions.

Looking beyond the mean, in Figure 3, we plot the sample distribution of the numbers of yellow cards awarded to the home and away teams, comparing matches with and without fans. The distribution for home yellows is similar in both cases, with $30 \%$ of matches having the modal number of two cards. But the modal number of away yellows was reduced to one from two when matches were played behind closed doors. More matches in empty stadiums had zero away yellows than when fans were present, and less had two, three, four and five yellows. In other words, there is a clear shift in the distribution of yellow cards awarded to away teams behind closed doors. 
TABLE 5: Comparison of sample means for discipline between matches with fans and without, 2002/03-2019/20

$\begin{array}{lll}\text { With fans } & \text { Closed doors } & \text { Diff. } \\ \text { (I) } & \text { (II) } & \text { (III) }\end{array}$

\begin{tabular}{|c|c|c|c|}
\hline \multicolumn{4}{|l|}{ All } \\
\hline Home yellow cards & 1.93 & 1.93 & 0.01 \\
\hline Away yellow cards & 2.28 & 1.90 & $0.38^{* * *}$ \\
\hline Home red cards $>0$ & 0.11 & 0.14 & -0.03 \\
\hline Away red cards $>0$ & 0.15 & 0.12 & 0.04 \\
\hline Home penalties against $>0$ & 0.07 & 0.07 & 0.00 \\
\hline Away penalties against $>0$ & 0.11 & 0.14 & -0.03 \\
\hline \multicolumn{4}{|c|}{ European Competition (UEFA) } \\
\hline Home yellow cards & 1.70 & 1.50 & 0.20 \\
\hline Away yellow cards & 2.13 & 1.89 & 0.24 \\
\hline Home red cards $>0$ & 0.08 & 0.08 & 0.00 \\
\hline Away red cards $>0$ & 0.11 & 0.11 & 0.01 \\
\hline Home penalties against $>0$ & 0.06 & 0.08 & -0.02 \\
\hline Away penalties against $>0$ & 0.10 & 0.16 & -0.05 \\
\hline \multicolumn{4}{|l|}{ Italy } \\
\hline Home yellow cards & 2.10 & 2.16 & -0.05 \\
\hline Away yellow cards & 2.40 & 2.00 & $0.40^{* *}$ \\
\hline Home red cards $>0$ & 0.13 & 0.17 & -0.05 \\
\hline Away red cards $>0$ & 0.17 & 0.12 & 0.04 \\
\hline Home penalties against $>0$ & 0.08 & 0.07 & 0.01 \\
\hline Away penalties against $>0$ & 0.11 & 0.15 & -0.04 \\
\hline \multicolumn{4}{|l|}{ Serie A \& Ligue 1 (Elite) } \\
\hline Home yellow cards & 1.86 & 1.91 & -0.47 \\
\hline Away yellow cards & 2.21 & 1.57 & $0.64^{* * *}$ \\
\hline Home red cards $>0$ & 0.10 & 0.15 & -0.05 \\
\hline Away red cards $>0$ & 0.10 & 0.15 & -0.00 \\
\hline Home penalties against $>0$ & 0.07 & 0.06 & 0.02 \\
\hline Away penalties against $>0$ & 0.11 & 0.13 & -0.02 \\
\hline
\end{tabular}

Notes.- $* * *, * * *$ indicate significant differences in means between matches with fans and without at $0.1 \%, 1 \%$ and $5 \%$ levels, respectively, two-sided $t$-tests. See Table 1 for $N$ s. Source.- author calculations using worldfootball.net; accessed 14 March 2020. 
FIGURE 3: Sample distribution of yellow cards awarded over matches: with fans vs without, 2002/03-2019/20

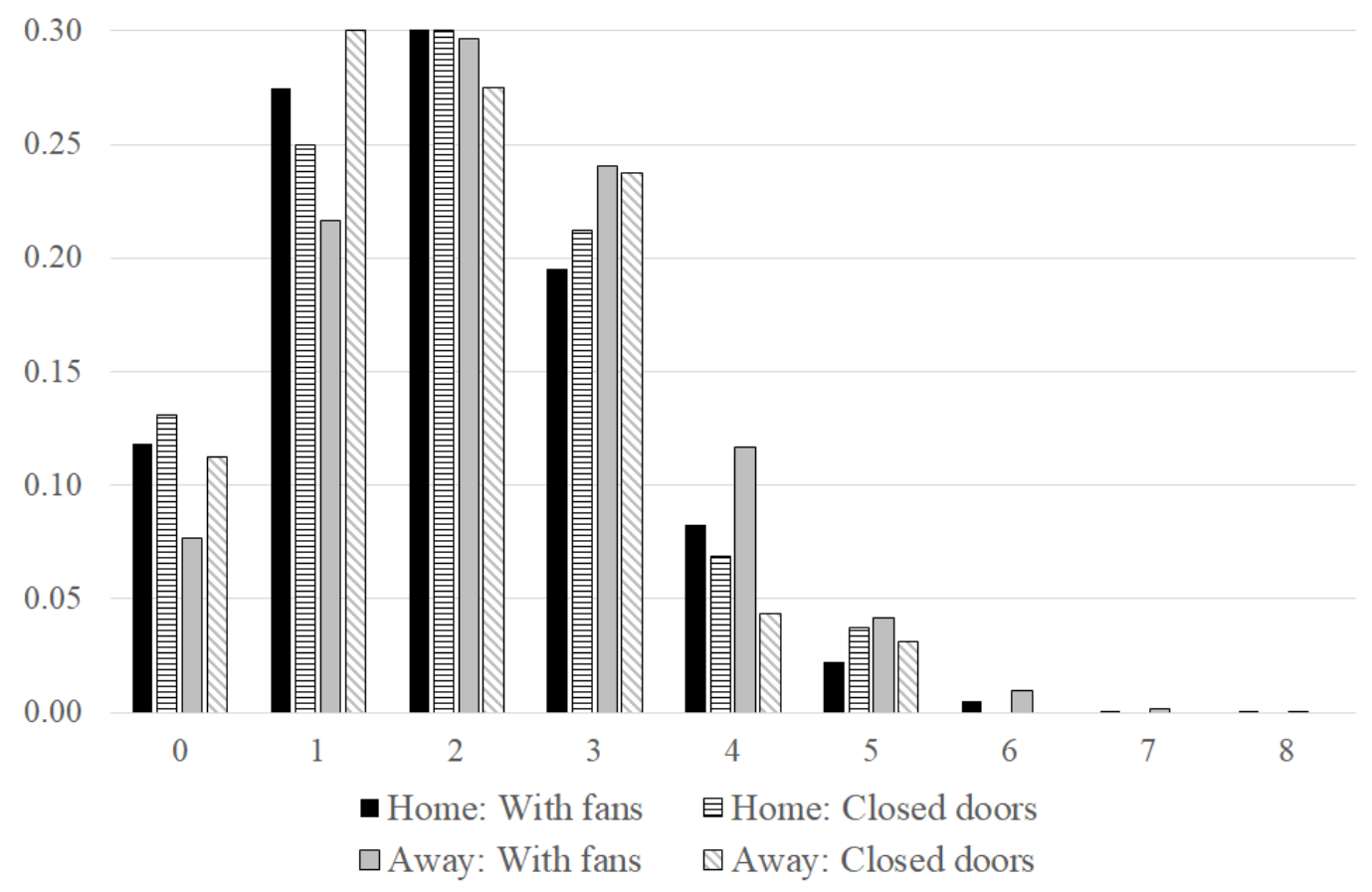

Notes.- All sample matches. Source.- worldfootball.net; accessed 14 March 2020.

\subsubsection{Home team regression results}

In Table 6, we show regression model estimates for the impact of playing matches behind closed doors on home team discipline. Rows $1 \& 2$ focus on yellow cards, with the first row only controlling for home-team-season heterogeneity, and the second row adding away-team-season fixed effects to the model. Rows $3 \& 4$ show LPM estimates for whether or not the home team was awarded a red card or gave away a penalty, using our preferred specification of the error term in Equation (1). Finally, row 5 looks at the number of fouls in a match committed by home team using the sub-samples where this information was available. ${ }^{9}$ Across all these different regression models and the UEFA, Italy and Elite sub-samples, we find no evidence that home team punishments were affected by a match being played behind closed doors, at standard levels of statistical significance.

\footnotetext{
${ }^{9}$ The total (closed doors) numbers of matches in the sample for which fouls data were available from espn.co.uk/football are: All, 13,265 (64); UEFA, 3,461 (31); Elite, 9635 (33).
} 
TABLE 6: Regression model estimates of the effect of playing matches behind closed doors on home team discipline, 2002/03-2019/20

\begin{tabular}{lcccc}
\hline & $\begin{array}{c}\text { All } \\
\text { (I) }\end{array}$ & $\begin{array}{c}\text { UEFA } \\
(\mathrm{II})\end{array}$ & $\begin{array}{c}\text { Italy } \\
(\mathrm{III})\end{array}$ & $\begin{array}{c}\text { Elite } \\
\text { (IV) }\end{array}$ \\
\hline All yellow cards & & & & \\
1. Home-season FEs & -0.017 & -0.148 & 0.054 & -0.035 \\
& $(0.10)$ & $(0.31)$ & $(0.12)$ & $(0.15)$ \\
2. + away-season FEs & -0.142 & -0.084 & -0.147 & -0.125 \\
& $(0.11)$ & $(0.45)$ & $(0.12)$ & $(0.16)$ \\
\cline { 2 - 5 } Others & & & & \\
3. Red cards $>0$ & 0.010 & -0.133 & 0.046 & 0.049 \\
& $(0.03)$ & $(0.08)$ & $(0.04)$ & $(0.06)$ \\
4. Penalties against $>0$ & -0.034 & -0.079 & -0.028 & -0.046 \\
& $(0.03)$ & $(0.09)$ & $(0.03)$ & $(0.04)$ \\
5. Fouls & 0.009 & 0.077 & & 0.225 \\
& $(0.58)$ & $(1.32)$ & & $(0.74)$ \\
\hline
\end{tabular}

Notes.- $* * * * * *$ indicate significance from zero at $0.1 \%, 1 \%$ and $5 \%$ levels, respectively, two-sided tests, home-team-season cluster robust standard errors are displayed in parentheses (described in text). All regression models should be interpreted as linear (probability) models, unless stated otherwise below (see Equation (1)). All models include as control variables: home team Elo rating, away team Elo rating and match attendance. 1. number of yellow cards awarded to the home team, home-team-season fixed effects included only; 2. adds away-team-season fixed effects to $1 ; 3$. whether the home team was awarded at least one red card, equiv. to $2 . ; 4$. whether at least one penalty was awarded against the home team, equiv. to $2 ; 5$. number of fouls committed by the home team, equiv. to 2 . Source.author calculations using worldfootball.net and espn.co.uk/football; accessed 14 March 2020.

\subsubsection{Away team regression results}

In the first two rows of Table 7, we show estimates equivalent to the same rows in Table 6, changing the dependent variable to the number of yellow cards awarded to the away team. Controlling for both home and away team season-level heterogeneity in row 2, our preferred specification, the disproportionate effect of playing behind closed doors in all sample matches is a decrease of 0.36 yellow cards ( $p$-value $<0.01$ ). This effect is insignificant in the UEFA competitions, but larger in the Italy and Elite sub-samples, -0.43 ( $p$-value $<0.001$ ) and -0.82 ( $p$-value $<0.001$ ) cards, respectively. The linear attendance control variable in these regressions, not displayed in the table, implies that 1,000 fewer spectators decreases the number of away yellow cards awarded by 0.008 ( $p$-value $<0.001$; row 2 , column (I)). For the median or mean stadium attendances in the samples, (see Table 1) the closed doors effect by itself, $\hat{\lambda}$, is substantially larger than the cumulative linear effect, $\widehat{\beta}_{1}$, of going down to zero spectators from the stadium average. At the Elite level, the linear attendance effect was statistically insignificant (row 2, column (IV)). ${ }^{10}$

\footnotetext{
${ }^{10}$ We estimated the models in row 2 of Table 7 with the addition of a squared attendance term, finding that this tended to lead to a small decrease in the estimated effect of playing behind closed doors, i.e., a greater magnitude, but the adjusted R-squared was not improved; results available on request.
} 
TABLE 7: Regression model estimates of the effect of playing matches behind closed doors on away team discipline, 2002/03-2019/20

\begin{tabular}{lcccc}
\hline & $\begin{array}{c}\text { All } \\
(\mathrm{I})\end{array}$ & $\begin{array}{c}\text { UEFA } \\
(\mathrm{II})\end{array}$ & $\begin{array}{c}\text { Italy } \\
(\mathrm{III})\end{array}$ & $\begin{array}{c}\text { Elite } \\
(\mathrm{IV})\end{array}$ \\
\hline All yellow cards & & & & \\
1. Away-season FEs & $-0.501^{* * *}$ & -0.310 & $-0.544^{* * *}$ & $-0.805^{* * *}$ \\
& $(0.09)$ & $(0.24)$ & $(0.12)$ & $(0.15)$ \\
2. + home-season FEs & $-0.359^{* *}$ & 0.188 & $-0.428^{* * *}$ & $-0.816^{* * *}$ \\
& $(0.11)$ & $(0.46)$ & $(0.13)$ & $(0.17)$ \\
3. Match-up FEs & $-0.565^{* * *}$ & & $-0.573^{* * *}$ & $-0.748^{* * *}$ \\
& $(0.11)$ & & $(0.13)$ & $(0.16)$ \\
4. + referee FEs & $-0.541^{* * *}$ & -0.349 & $-0.555^{* * *}$ & $-0.850^{* * *}$ \\
& $(0.10)$ & $(0.29)$ & $(0.12)$ & $(0.15)$ \\
5. Poisson & $-0.168^{* * *}$ & 0.130 & $-0.190^{* * *}$ & $-0.426^{* * *}$ \\
& $(0.05)$ & $(0.16)$ & $(0.06)$ & $(0.09)$ \\
\cline { 2 - 5 } Others & & & & \\
6. Red cards $>0$ & -0.033 & 0.150 & $-0.078^{*}$ & -0.024 \\
7. Straight red cards $>0$ & $(0.02)$ & $(0.09)$ & $(0.04)$ & $(0.06)$ \\
& 0.007 & 0.080 & -0.007 & 0.005 \\
8. 2nd Yellows $>0$ & $(0.03)$ & $(0.06)$ & $(0.03)$ & $(0.05)$ \\
& $-0.048^{*}$ & 0.079 & $-0.079^{* *}$ & -0.047 \\
9. Penalties against $>0$ & $(0.02)$ & $(0.08)$ & $(0.02)$ & $(0.04)$ \\
& 0.009 & -0.017 & 0.017 & 0.017 \\
10. Fouls & $(0.03)$ & $(0.11)$ & $(0.04)$ & $(0.05)$ \\
11. Yellows/Fouls & 0.041 & 0.333 & & -0.094 \\
12. Away-Home yellow cards & $(0.82)$ & $(1.62)$ & & $(0.98)$ \\
& -0.020 & 0.039 & & $-0.043^{* *}$ \\
& $(0.02)$ & $(0.05)$ & & $(0.02)$ \\
& -0.231 & 0.389 & -0.327 & $-0.691^{* * *}$ \\
& $(0.15)$ & $(0.60)$ & $(0.18)$ & $(0.21)$ \\
\hline
\end{tabular}

Notes.- ***,*** indicate significance from zero at $0.1 \%, 1 \%$ and $5 \%$ levels, respectively, two-sided tests, away-team-season cluster robust standard errors are displayed in parentheses (described in text). All regression models should be interpreted as linear (probability) models, unless stated otherwise below (see Equation (1)). All models include as control variables: home team Elo rating, away team Elo rating and match attendance. 1. number of yellow cards awarded to the away team, away-team-season fixed effects included only; 2. adds home-team-season fixed effects to $1 ; 3$. home-team-away-team (match-up) fixed effects instead; 4. adds home-team-season fixed effects to $1 ; 5$. Poisson count model equiv. of 2 , estimated coefficients should be interpreted as the difference in expected log yellow cards between closed doors matches and those with fans; 6 . whether the away team was awarded at least one red card, equiv. to $2 ; 7$. whether the away team was awarded at least one straight red card, equiv. to 2 ; 8 . whether at least one away team player was awarded a second yellow card, equiv. to $2 ; 9$. whether at least one penalty was awarded against the away team, equiv. to $2 ; 10$. number of fouls committed by the away team, equiv. to $2 ; 11$. yellow cards per foul, equiv. to $2 ; 12$. Away minus home yellow cards (all), equiv. to 2. Source.- author calculations using worldfootball.net and espn.co.uk/football; accessed 14 March 2020. 
In row 3 of Table 7, we show that the effects of playing without fans on away yellow cards are also large and statistically significant within specific match ups (or fixtures). Likewise, row 4 shows that the effects are marginally higher when we control for the selection of different referees into closed doors matches. In row 5, we check whether the results are robust to using a non-linear Poisson regression model, which reflects the count nature of yellow cards within matches. The displayed coefficients should be interpreted as the log change in the expected number of away yellow cards. The Poisson model effects are statistically significant, except in the UEFA competitions, and translate into similar magnitudes of effects as in the linear model of row 2: e.g., $\exp (-0.168)=$ 0.845 and the mean number of away yellow cards is 2.3 , implying a marginal effect of approximately 0.35 fewer cards per match; row 5 , column (I).

In rows 6-12 of Table 7, we show estimates from our preferred specification of Equation (1), varying the dependent variable with other measures of discipline or punishment against the away team. In Italy, row 6 , the probability of seeing a red card awarded to the away team without fans is reduced by 0.08 ( $p$-value $<0.05$ ), but this effect is not significant overall or in the UEFA and Elite sub-samples. The Italian effect is not driven by the awarding of straight red cards (row 7), but instead by the decreased likelihood of a second yellow card without fans (row 8). Row 9 shows that at least one penalty kick awarded against the away team is no more or less likely with than without fans. Likewise, the number of fouls committed by the away team is not significantly different when a match is played behind closed doors, conditional on general attendance effects and the identities of the teams involved. Row 11 tests whether the number of yellows cards per foul committed decreases in an empty stadium. This is the case at the Elite level, by 0.04 cards per foul ( $p$-value $<0.01$ ). This suggests that the punishment handed out by the referee per foul by the away team is less severe behind closed doors. Finally, row 12 looks to test more directly the referee bias in punishments within a match, by looking at the effect of there being fans or not on the difference between the numbers of yellow cards awarded to the away and home teams. This difference is reduced without fans across all matches and in Italy, but not significantly. In the small sample of UEFA closed doors matches, the referee bias in yellow cards increases, but also not significantly. At the Elite level, playing a match behind closed doors leads to a 0.69 ( $p$-value $<0.001$ ) reduction of the normal referee bias toward more yellow cards for the away team. We use the term 'referee bias' bias in describing these estimates only suggestively, as we have not yet addressed the possibility that the effects are driven by changes in player behaviour.

The results in this section, and their suggestion of how referee bias interacts with a football crowd, do not dovetail perfectly with what PLP found in just twenty-one matches in empty Italian stadiums in 2006/07. PLP found significantly fewer yellow cards awarded to both the home and the away teams without fans, with the difference between them narrowing, as well as significantly fewer fouls awarded against the away team. By increasing the sample of closed doors matches here, generalising to other competitions outside of Italy, and controlling for the selection of team attributes into these matches, we find that only the negative impact of playing without fans on the number of yellow cards awarded to the away team is convincingly robust. 


\subsection{Injury time}

For a smaller sample of matches, we have information on the amount of injury time awarded by referees. In Table 8 and Figure 4, we compare the sample means for these decisions with and without fans. ${ }^{11}$ Injury time in football is at the discretion of the referee, and should reflect how disrupted the play was by stoppages during a half. One rule that referees are supposed to apply is the addition of thirty seconds for each player substitution, which mostly take place in the second half. In column (I) of Table 8, we show that on average, with fans in the stadium, over two minutes more injury time was awarded at the end of the second half compared with the first half.

Several studies have pointed toward injury time as a way in which referee bias relates to home advantage in football (e.g., Sutter and Kocher, 2004; Garicano et al., 2005; Dohmen, 2008b; Scoppa, 2008). Specifically, if a referee is affected by social pressure form the home crowd, then we might expect him/her to award more injury time when the home team is losing at the end of 90 minutes, allowing a greater chance for them to catch up, and vice versa if the home team is winning. We would also expect these effects to disappear if the absolute goal difference between the home and away team at the end of regular time is large enough that the final result is effectively already decided, normally two goals or more, because then there will be less pressure from the home crowd, many of whom may already be on their way to the car park.

In Table 8, we show the average amount of injury time awarded in the second half of matches depending on the goal difference at 90 minutes. More time was generally awarded when a match was close, and more so when the away team was leading by a single goal. This was the case in both the UEFA and Elite competitions, and is consistent with what the previous literature has found about the effects of social pressure on referee bias. In columns (II) \& (III) of Table 8, we show that the amount of injury time awarded in both the first and second half was on average significantly less, by 0.3-0.4 minutes ( $p$-value $<0.05$ ), in the pooled sample of closed doors matches. But there is no evidence that this decrease was associated with whatever the match scoreline was at 90 minutes. Because of the small sample size, we don't carry out any regression analysis of injury time and how it depended on match situations. But this could be an area of interest for future research as the number of closed doors matches increases during the Covid-19 outbreak. Not least, one way to definitively test whether referee bias exists in the awarding of injury time, affected by the presence of fans, would be to look at the impact from the number of substitutions, since these should each result in an additional 30 seconds regardless of which team made them.

\footnotetext{
${ }^{11}$ The total (closed doors) numbers of matches in the sample for which injury time details were available from espn.co.uk/football are: All, 13,331 (77); UEFA, 3,427 (31); Elite, 9904 (46).
} 
TABLE 8: Comparison of sample means of injury time (mins) between matches with fans and without, 2002/03-2019/20

\begin{tabular}{|c|c|c|c|}
\hline & $\begin{array}{l}\text { With fans } \\
\text { (I) }\end{array}$ & $\begin{array}{l}\text { Closed doors } \\
\text { (II) }\end{array}$ & $\begin{array}{l}\text { Diff. } \\
\text { (III) }\end{array}$ \\
\hline \multicolumn{4}{|l|}{ All } \\
\hline 1st half & 1.93 & 1.58 & $0.34^{*}$ \\
\hline 2nd half & 4.10 & 3.69 & $0.41^{*}$ \\
\hline 2nd half: away $>1$ up at 90 mins & 3.68 & 2.83 & 0.85 \\
\hline 2nd half: away 1 up at 90 mins & 4.44 & 4.00 & 0.44 \\
\hline 2nd half: even at 90 mins & 4.28 & 3.60 & 0.68 \\
\hline 2nd half: home 1 up at 90 mins & 4.26 & 3.82 & 0.44 \\
\hline 2nd half: home $>1$ up at 90 mins & 3.53 & 4.10 & -0.57 \\
\hline \multicolumn{4}{|l|}{ European Competition (UEFA) } \\
\hline 1st half & 1.47 & 1.23 & 0.24 \\
\hline 2nd half & 3.11 & 2.55 & 0.57 \\
\hline 2nd half: away $>1$ up at 90 mins & 3.08 & 1.6 & 1.48 \\
\hline 2nd half: away 1 up at 90 mins & 3.34 & 3.10 & 0.24 \\
\hline 2nd half: even at 90 mins & 3.12 & 2.60 & 0.52 \\
\hline 2nd half: home 1 at 90 mins & 3.15 & 2.20 & 0.95 \\
\hline 2nd half: home $>1$ up at $90 \mathrm{mins}$ & 2.93 & 3.00 & -0.07 \\
\hline \multicolumn{4}{|l|}{ Serie A \& Ligue 1 (Elite) } \\
\hline 1 st half & 2.09 & 1.83 & 0.26 \\
\hline 2nd half & 4.43 & 4.46 & -0.02 \\
\hline 2nd half: away $>1$ up at 90 mins & 3.92 & 3.71 & 0.21 \\
\hline 2nd half: away 1 up at 90 mins & 4.83 & 5.13 & -0.30 \\
\hline 2nd half: even at 90 mins & 4.64 & 4.60 & 0.04 \\
\hline 2nd half: home 1 at 90 mins & 4.64 & 4.50 & 0.14 \\
\hline 2nd half: home $>1$ up at $90 \mathrm{mins}$ & 3.76 & 4.22 & -0.46 \\
\hline
\end{tabular}

Notes.- $* * * * * *$ indicate significant differences in means between matches with fans and without at $0.1 \%, 1 \%$ and $5 \%$ levels, respectively, two-sided $t$-tests. See Table 1 for $N$ s. Source.- author calculations using worldfootball.net and espn.co.uk/football; accessed 14 March 2020. 
FIGURE 4: Differences in sample means of injury time awarded, depending on the match situation at 90 mins: closed doors vs with fans, 2002/03-2019/20

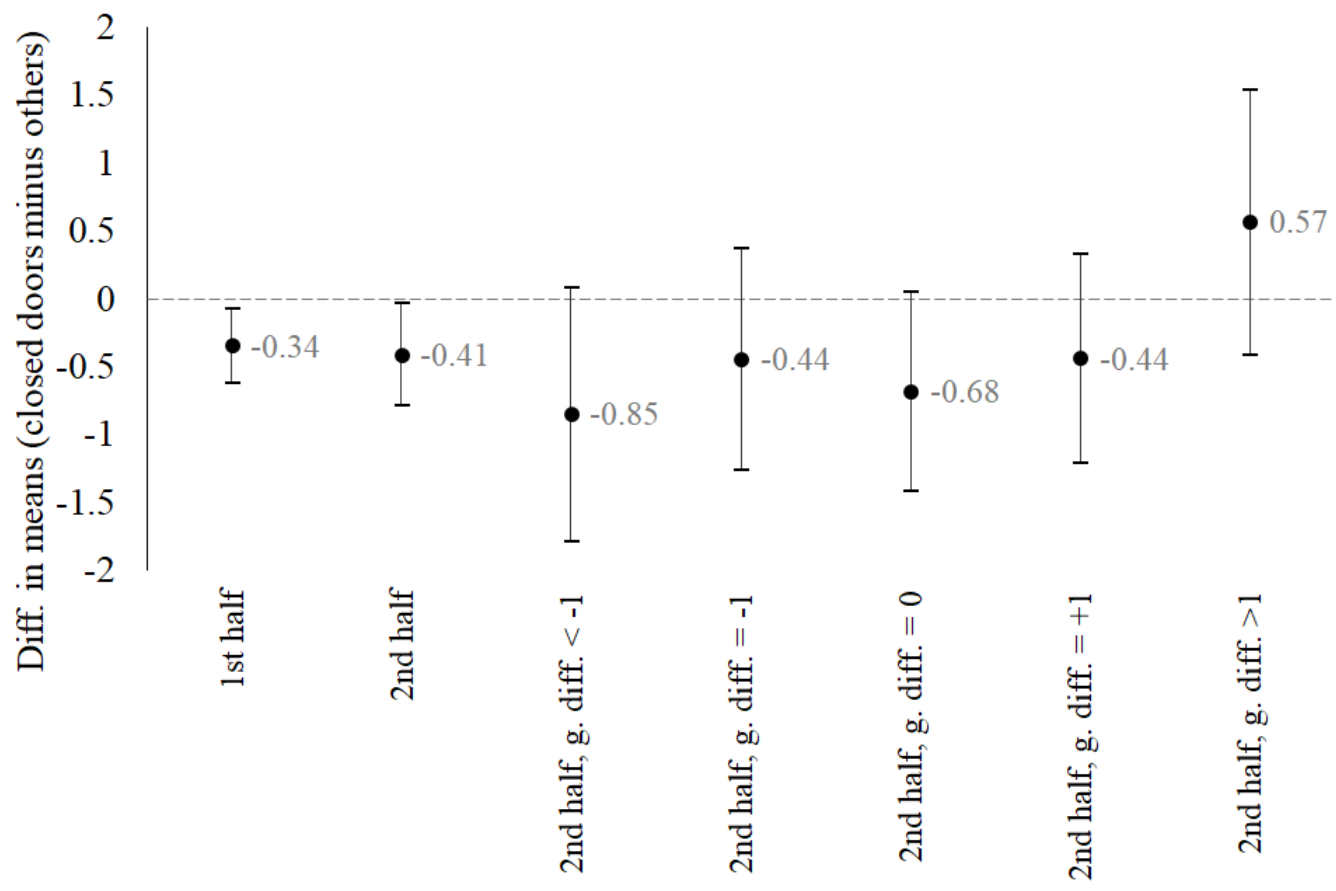

Notes.- "2nd half g. diff $=-1$ " refers to matches where at 90 minutes the away team was leading by one goal, etc. Uses all matches in the UEFA Champions League, Europa League, Italian Serie A, and French Ligue 1 since the beginning of the 2002/03 season. See Figure 1 and Tables 1-2 for further sample description. 95\% confidence intervals displayed. Source.- author calculations using worldfootball.net and espn.co.uk/football; accessed 14 March 2020.

\subsection{Player performances}

The results above suggest that the presence or not of fans in stadiums probably affects home advantage in football through the decision making of the referee. But it is possible that changes in the nature of match play also have a role and, for example, could account for the reduced number of yellow cards awarded to away team players. To explore this further, we look at several metrics of player performance within matches. In Table 9 and the final seven statistics in Figure 2, we compare the sample means of these metrics between matches with and without fans. ${ }^{12}$ The average amount of ball possession in closed doors matches was 50.0\%, an insignificant reduction of 1.1 percentage compared with when fans were allowed into stadiums. Whether a penalty kick leads directly to a goal is an outcome which ought to be almost entirely independent of the referee, apart from the rare cases where the referee deems a kick must be retaken for some infringement. In matches behind closed doors, fewer (more) penalty kicks were missed (saved) by away team players and more (fewer) were missed (saved) by home team players. Though these difference were not statistically significant, owing to the small sample sizes, they are consistent with home support motivating and improving home team player performances but distracting and worsening away team

\footnotetext{
${ }^{12}$ The information on penalty kicks is available for all sample matches, but the other metrics are only available for the same smaller samples in which fouls were studied in Section 4.2.
} 
player performances. These events could be looked at more closely in future research, not least because past studies have found evidence of athletes choking under the pressure of home support and the size of the crowd (e.g., Dohmen, 2008a in football, Böheim et al., 2019 in basketball and Harb-Wu and Krumer, 2019 in biathlon).

In Table 9, we also show that the percentages of shots on target, i.e., shots that would have always led to a goal without being blocked, were greater in closed doors matches than with fans, though not significantly so. But the percentage of shots on target which were saved was significantly higher in closed doors matches, by 10 and 12 percentage points ( $p$-value $<0.05$ ) for home and away team goalkeepers, respectively. This pattern was prevalent in both the UEFA and Elite competitions. One potential explanation would be that goalkeepers were less distracted by crowd noise without fans and their performances improved. Another explanation would be that shots were easier to save behind closed doors, perhaps because the ball contrasted more with the background of empty seats or players were shooting further away from the goal, although the the percentage of shots on target was not significantly different without fans.

TABLE 9: Comparison of player performance sample means between matches with fans and without, 2002/03-2019/20

\begin{tabular}{lccc}
\hline & $\begin{array}{c}\text { With fans } \\
\text { (I) }\end{array}$ & $\begin{array}{c}\text { Closed doors } \\
\text { (II) }\end{array}$ & $\begin{array}{c}\text { Diff. } \\
\text { (III) }\end{array}$ \\
\hline All & & & \\
Home possession (\%) & 51.1 & 50.0 & 1.1 \\
Home penalties missed (\%) & 21.2 & 27.3 & -6.1 \\
Away penalties missed (\%) & 20.4 & 9.1 & 11.4 \\
Home shots on target (SOT) (\%) & 35.0 & 36.0 & -1.0 \\
Away shots on target (SOT) (\%) & 34.3 & 37.2 & -2.9 \\
Home SOT saved (\%) & 73.8 & 83.7 & $-12.5^{* *}$ \\
Away SOT saved (\%) & 72.4 & 84.9 & \\
European Competition (UEFA) & & & 3.0 \\
Home possession (\%) & 51.4 & 48.4 & -4.1 \\
Home shots on target (SOT) (\%) & 37.5 & 41.6 & -5.7 \\
Away shots on target (SOT) (\%) & 37.1 & 45.5 & -11.2 \\
Home SOT saved (\%) & 85.6 & 91.4 & \\
Away SOT saved (\%) & 85.8 & 97.1 & -0.5 \\
Serie A \& Ligue 1 (Elite) & & & 3.4 \\
Home possession (\%) & 51.0 & 51.5 & 3.9 \\
Home shots on target (SOT) (\%) & 34.1 & 30.7 & -6.4 \\
Away shots on target (SOT) (\%) & 33.3 & 29.4 & -5.7 \\
Home SOT saved (\%) & 69.7 & 76.1 & 73.4 \\
Away SOT saved (\%) & 67.7 & & \\
\hline
\end{tabular}

Notes.- $* * *, * * *$ indicate significant differences in means between matches with fans and without at $0.1 \%, 1 \%$ and $5 \%$ levels, respectively, two-sided $t$-tests. See Table 1 for $N$ s. Source.- author calculations using worldfootball.net and espn.co.uk/football; accessed 14 March 2020. 
In Table 10, we show regression model estimates of the impact of playing behind closed doors on five different football performance metrics, using the preferred specification of Equation (1): the percentages of shots on target by home and away players; the percentages of those shots that were saved by home and away goalkeepers; and the home ball possession percentage. Conditional on the strengths and form of both teams taking part, playing without fans tends to increase home possession, decrease the percentage of shots on target and increase the percentage of shots on target that are saved. But these effects are generally not significant. Tentatively, because this particular analysis is lacking statistical power due to the small number of closed doors matches with the required information, the results suggest that major changes in match play are unlikely to account for less home advantage and referee bias against the away team in an empty stadium. This is consistent with what PLP found in their smaller sample of Italian matches.

TABLE 10: Regression model estimates of the effect of playing matches behind closed doors on player performances, 2002/03-2019/20

\begin{tabular}{lccc}
\hline & $\begin{array}{c}\text { All } \\
(\mathrm{I})\end{array}$ & $\begin{array}{c}\text { UEFA } \\
\text { (II) }\end{array}$ & $\begin{array}{c}\text { Elite } \\
\text { (III) }\end{array}$ \\
\hline Home team & & & \\
1. Possession (\%) & 1.87 & 1.46 & 1.99 \\
& $(0.98)$ & $(2.44)$ & $(1.11)$ \\
2. Shots on target (SOT) (\%) & -0.94 & 3.67 & -2.86 \\
& $(2.40)$ & $(5.39)$ & $(2.99)$ \\
3. SOT saved (\%) & 0.97 & 2.79 & 2.08 \\
& $(4.76)$ & $(16.43)$ & $(4.72)$ \\
Away team & & & $-7.73^{*}$ \\
4. Shots on target (SOT) (\%) & -2.98 & 0.33 & $(3.09)$ \\
& $(2.77)$ & $(6.64)$ & 7.87 \\
5. SOT saved (\%) & 6.61 & 6.11 & $(4.64)$ \\
\hline
\end{tabular}

Notes.- $* * *, * * *$ indicate significance from zero at $0.1 \%, 1 \%$ and $5 \%$ levels, respectively, two-sided tests, home/away-team-season cluster robust standard errors are displayed in parentheses (described in text). All models include as control variables: home team Elo rating, away team Elo rating, match attendance, home-team-season fixed effects and away-team-season fixed effects (see Equation (1)). Source.- author calculations using worldfootball.net and espn.co.uk/football; accessed 14 March 2020.

\section{What has happened to home advantage since Covid-19?}

The first major European football league to return after Covid-19 had shut down the sporting calendar was the German Bundesliga on $16^{\text {th }}$ May 2020, over two months after the last match was played. All matches in Germany since then have taken place behind closed doors. While we could replicate the above analysis for these matches, we are reluctant to do so, as it is not as clear as in the pre-Covid-19 data that the presence of fans is the only thing that has changed. Temporary new rules on the number and timing of substitutions in matches have been introduced, which could affect tactics and play. Further, it is plausible that the presence of the virus has altered the competitiveness of matches, with 
players avoiding close contact and referees becoming more protective, resulting in either more or less fouls and punishments. We believe that studying these issues is better suited to future research, when more professional leagues have returned to action and more matches have been played, exploiting variation between countries and over time in the new rule changes. Further, in some leagues that have returned to action, rather than being behind closed doors, limited numbers of socially distanced fans are being allowed into stadiums, such as in Hungary and the Czech Republic. ${ }^{13}$ In addition, home teams throughout Europe have come up with initiatives to replace some of the atmosphere that is lost when the fans are absent. ${ }^{14}$

Followers of German football have taken to calling the new format of the Bundesliga "geisterspiele" or "ghost games". It has been widely noted that home advantage has not only disappeared but even reversed in these ghost games, with a statistically implausible sequence of results compared with normal times. ${ }^{15}$ Between the return from the league's shutdown and $14^{\text {th }}$ June 2020 , home teams in the Bundesliga, had won just $20 \%$ of the matches played (11 of 55, compared with $43 \%$ in the same season before March. Away teams, however, had won 51\% (28 of 55) of the post-shutdown matches, compared with $35 \%$ in the season beforehand. Similar patterns have been observed in other leagues that have returned and played a reasonable number of matches behind closed doors, such as in Estonia and the Czech Republic. Commenting on this, one Bundesliga team manager stated that he was not surprised as: "Without Spectators, it comes down more to the quality of players." 16 Referees and players in Germany have also described the effects of there being no fans, with at least one example of the former describing a lack of emotion in games and the latter claiming that motivation had decreased. ${ }^{17}$

To put this apparent recent reduction in home advantage in European professional football into perspective, and to generalise beyond the German Bundesliga, we collected the result outcomes since 2016 of all football played in top professional leagues, including those that have returned early after the Covid-19 suspension. On the right panel of Figure 5, we show the monthly averages in the proportions of matches ending in a home win, draw and away win. Home advantage throughout these leagues completely disappeared in May 2020, with an identical number of matches being won by the home team as the away team. In June, the pattern has changed slightly, with more home wins, but the relatively high level of away wins has not abated. To put these recent trends into context, the left-hand panel of Figure 5 plots the proportion of matches ending in home wins, draws and away wins on an annual basis back to 1890. This shows the persistent and substantial decline in home advantage over the decades, but even in 2020 taken as a whole, $44 \%$ of matches have ended in home wins, rather than the $36.5 \%$ recorded in May 2020. These patterns deserve further attention going

\footnotetext{
${ }^{13}$ In Hungary, from June 2020 only one seat in every four can be occupied within stadiums; CNN, $31^{\text {st }}$ May 2020 , https://edition.cnn.com/2020/05/31/football/hungary-football-fans-return-spt-intl/index.html.

${ }^{14}$ For example, a team in Denmark has introduced a virtual grandstand so that fans can feel present at home games; BBC Sport, 28 ${ }^{\text {th }}$ May 2020, https://www.bbc.co.uk/sport/football/52843806.

${ }^{15}$ See for example ESPN, $9^{\text {th }}$ June 2020; https://www.espn.co.uk/football/german-bundesliga/story/4107639/.

${ }^{16}$ Bayer Leverkusen manager Peter Bosz, reported on the team's official website, $25^{\text {th }}$ May, 2020.

${ }^{17}$ See for example ESPN, $9^{\text {th }}$ June 2020; https://www.espn.co.uk/football/german-bundesliga/story/4107639/.
} 
forward, to discern whether it is the lack of social pressure from spectators that is causing these unusual outcomes, and, if so, what the mechanisms are, or whether other factors are at play.

FIGURE 5: Professional football result outcomes since 1890 (left panel), and between January 2016 to June 2020 (right panel)
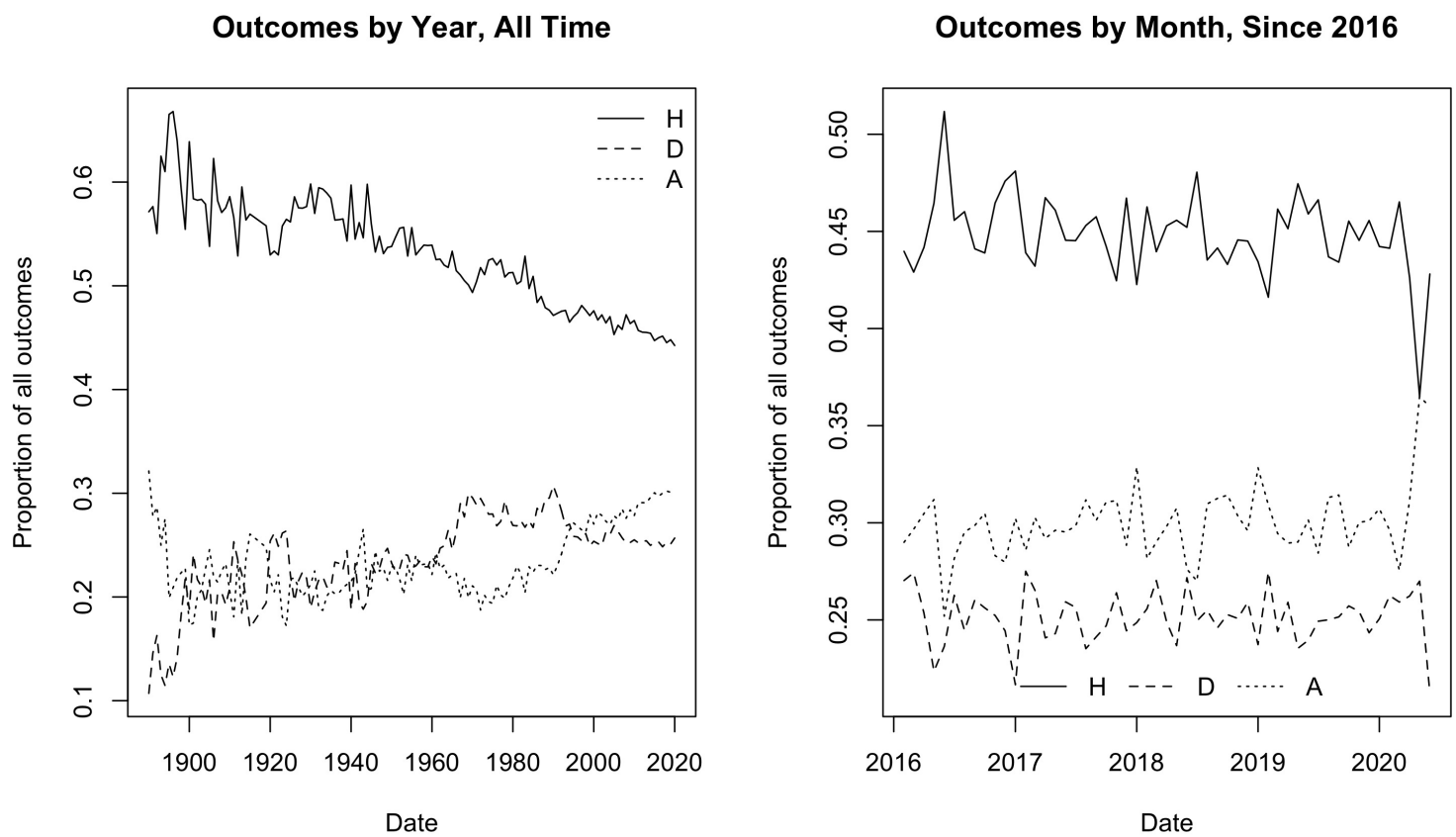

Notes.- "H" refers to home wins, "D" refers to draws and "A" refers to away wins. Uses all matches in the top leagues of 108 countries or regions since 1890, 82 countries since January 2016, and 29 in May and June 2020. Source.- author calculations using worldfootball.net; accessed 16 June 2020.

\section{Concluding remarks}

In this paper, we investigated the impact of social pressure on the outcomes of historical European football matches. We exploited the rare instances when professional and competitive matches were played behind closed doors, treating these as natural experiments, where the only factor varied was the presence or not of the fans in the stadium. We found that the substantial and commonly observed home advantage in football was disproportionately eroded when fans were absent, although not completely once we controlled for the selection of different teams into these relatively rare events. The standout effect of playing behind closed doors was the decreased severity of punishments for the away team, mainly through the reduced number of yellow cards awarded for foul play. This suggests that the referee is normally affected by the social pressure of a predominantly home team supporting crowd, thus punishing the away team players more severely. These results contribute to a wide literature that has also found evidence that home advantage in professional sports can be in part attributed to the unconscious bias of those officiating (e.g., Dohmen and Sauermann, 2016). 
The results in this paper could have implications for the competitive balance of sports leagues and demand. Home advantage ensures that a weak team playing in its own stadium often has a good chance of beating a strong team (Forrest et al., 2005). If this effect is greater for weaker teams, then without it strong teams would win more often and the competitive balance of leagues would be reduced. The evidence on the interaction between home advantage and team quality is limited. Bray et al. (2003) found in English football that home advantage in terms of wins was slightly greater for stronger teams, but weaker teams appeared to have a relatively greater advantage in earning draws at home. Rottenberg's 1956 "Uncertainty of Outcome Hypothesis", whereby sports demand increases the less certain is the outcome, has been shown to apply to football fans watching on television (e.g., Buraimo and Simmons, 2009; Cox, 2018; Schreyer et al., 2018a,b). This suggests that TV audience demand for league football could be affected if matches remain behind closed doors. Reduced home advantage should increase the attractiveness of matches featuring a strong home team and a weak away team, and vice versa when those relative strengths are reversed. In addition, there could be a second magnifying effect on demand, as changes in home advantage which are not equally distributed over team strengths would tend toward making the overall league championships more or less competitive, affecting the interest of fans. We should also be cautious in assuming that the reduction in home advantage observed in one-off historical matches behind closed doors transfers to the present situation in professional sport, where empty stadiums are becoming the norm. One potential explanation for home advantage is a team's familiarity with its surroundings. For example, there is evidence that sports teams who move to new stadiums only temporarily experience reduced home advantage (e.g., Pollard, 2002; Wilkinson and Pollard, 2006). Although our results suggest that the closed doors effect acts through the referees and their bias, this may diminish or alter if they and the other participants become accustomed to playing without spectators. More research is needed to unpick these issues, especially on whether the closed doors effect is greater for some teams than others.

From a behavioural perspective, ideally we would have isolated the actions of the different agents in a football match, i.e., the players, officials and managers, to identify more precisely the mechanisms through which outcomes are affected by playing behind closed doors. In the historical data considered here, this was not practical, as the small sample of matches without fans did not afford much statistical power. This is something that future research could look to address in the coming months, as European football continues alongside Covid-19 in empty stadiums. 


\section{References}

Ahammer, A., M. Halla, and M. Lackner. 2020. "Mass Gatherings Contributed to Early COVID-19 Spread: Evidence from US Sports.” Working paper.

Akerlof, G. 1980. “A Theory of Social Custom, of which Unemployment may be One Consequence." The Quarterly Journal of Economics, 94(4): 749-775.

Becker, G. S., and K. M. Murphy. 2000. Social Economics: Market Behavior in a Social Environment. Harvard University Press.

Belchior, C. A. 2020. "Fans and Match Results: Evidence From a Natural Experiment in Brazil." Journal of Sports Economics.

Bernheim, B. D. 1994. “A Theory of Conformity.” Journal of Political Economy, 102(5): 841-77.

Böheim, R., D. Grübl, and M. Lackner. 2019. "Choking under pressure - Evidence of the causal effect of audience size on performance.” Journal of Economic Behavior \& Organization, 168 76-93.

Boudreaux, C. J., S. D. Sanders, and B. Walia. 2017. "A Natural Experiment to Determine the Crowd Effect Upon Home Court Advantage.” Journal of Sports Economics, 18(7): 737-749.

Boyko, R., A. Boyko, and M. Boyko. 2007. "Referee bias contributes to home advantage in English Premiership football.” Journal of Sports Sciences, 25(11): 1185-1194.

Bray, S. R., J. Law, and J. Foyle. 2003. "Team Quality and Game Location Effects in English Professional Soccer.” Journal of Sport Behavior, 26(4): 319-334.

Buraimo, B., D. Forrest, and R. Simmons. 2010. "The 12th man?: refereeing bias in English and German soccer." Journal of the Royal Statistical Society: Series A (Statistics in Society), 173(2): 431-449.

Buraimo, B., and R. Simmons. 2009. "A tale of two audiences: Spectators, television viewers and outcome uncertainty in spanish football." Journal of Economics and Business, 61(4): 326-338.

Buraimo, B., R. Simmons, and M. Maciaszczyk. 2012. "Favoritism and referee bias in european soccer: Evidence from the spanish league and the uefa champions league." Contemporary Economic Policy, 30(3): 329-343.

Cardazzi, A., B. R. Humphreys, J. E. Ruseski, B. Soebbing, and N. Watanabe. 2020. "Professional Sporting Events Increase Seasonal Influenza Mortality in US Cities.” Working paper.

Charness, G., L. Rigotti, and A. Rustichini. 2007. "Individual Behavior and Group Membership." American Economic Review, 97(4): 1340-1352.

Charness, G., and M. Sutter. 2012. "Groups Make Better Self-Interested Decisions.” Journal of Economic Perspectives, 26(3): 157-76.

Clarke, S., and J. Norman. 1995. "Home Ground Advantage of Individual Clubs in English Soccer." Journal of the Royal Statistical Society. Series D (The Statistician), 44(4): 509-521.

Courneya, K. S., and A. V. Carron. 1992. "The Home Advantage In Sport Competitions: A Literature Review." Journal of Sport and Exercise Psychology, 14(1): 13-27.

Cox, A. 2018. "Spectator demand, uncertainty of results, and public interest." Journal of Sports Economics, 19(1): 3-30.

Dawson, P., and S. Dobson. 2010. "The influence of social pressure and nationality on individual decisions: Evidence from the behaviour of referees." Journal of Economic Psychology, 31(2): 181-191. 
Dawson, P., S. Dobson, J. Goddard, and J. Wilson. 2007. "Are football referees really biased and inconsistent?: evidence on the incidence of disciplinary sanction in the English Premier League." Journal of the Royal Statistical Society: Series A (Statistics in Society), 170(1): 231-250.

Dohmen, T. J. 2008a. “Do professionals choke under pressure?” Journal of Economic Behavior \& Organization, 65(3): 636-653.

Dohmen, T. J. 2008b. "The Influence Of Social Forces: Evidence From The Behavior Of Football Referees." Economic Inquiry, 46(3): 411-424.

Dohmen, T., and J. Sauermann. 2016. “Referee Bias.” Journal of Economic Surveys, 30(4): 679-695.

Elo, A. E. 1978. The Rating of Chessplayers, Past and Present. London Batsford.

Forrest, D., J. Beaumont, J. Goddard, and R. Simmons. 2005. "Home Advantage and the Debate About Competitive Balance in Professional Sports Leagues." Journal of Sports Sciences, 23(4): 439-445.

Garicano, L., I. Palacios-Huerta, and C. Prendergast. 2005. "Favouritism Under Social Pressure." The Review of Economics and Statistics, 87(2): 208-216.

Goller, D., and A. Krumer. 2020. "Let's meet as usual: Do games played on non-frequent days differ? Evidence from top European soccer leagues.” European Journal of Operational Research.

Goumas, C. 2014. "Home advantage and referee bias in European football." European Journal of Sport Science, 14(sup1): S243-S249, PMID: 24444213.

Harb-Wu, K., and A. Krumer. 2019. "Choking under pressure in front of a supportive audience: Evidence from professional biathlon.” Journal of Economic Behavior \& Organization, 166 246-262.

Hvattum, L. M., and H. Arntzen. 2010. "Using ELO ratings for match result prediction in association football.” International Journal of Forecasting, 26(3): 460-470.

Johnston, R. 2008. "On Referee Bias, Crowd Size, and Home Advantage in the English Soccer Premiership.” Journal of Sports Sciences, 26(6): 563-568.

Koyama, M., and J. J. Reade. 2009. "Playing Like the Home Team: An Economic Investigation Into Home Advantage in Football." International Journal of Sport Finance, 4(1): 16-41.

Neave, N., and S. Wolfson. 2003. “Testosterone, territoriality, and the 'home advantage'.” Physiology \& Behavior, 78(2): 269-275.

Nevill, A. M., and R. L. Holder. 1999. "Home Advantage in Sport: An Overview of Studies on the Advantage of Playing at Home." Sports Medicine, 28(4): 221-236.

Nevill, A., N. Balmer, and A. Williams. 2002. "The influence of crowd noise and experience upon refereeing decisions in football." Psychology of Sport and Exercise, 3(4): 261-272.

Page, K., and L. Page. 2010. "Alone against the crowd: Individual differences in referees' ability to cope under pressure." Journal of Economic Psychology, 31(2): 192-199.

Peeters, T., and J. C. van Ours. 2020. "Seasonal Home Advantage in English Professional Football; 1973-2018.” Tinbergen Institute Discussion Papers 20-025/V, Tinbergen Institute.

Pettersson-Lidbom, P., and M. Priks. 2010. "Behavior under social pressure: Empty Italian stadiums and referee bias.” Economics Letters, 108(2): 212-214.

Pollard, R., and G. Pollard. 2005. "Long-term trends in home advantage in professional team sports in North America and England (1876-2003).” Journal of Sports Sciences, 23(4): 337-350. 
Pollard, R. 1986. "Home advantage in soccer: A retrospective analysis." Journal of Sports Sciences, 4(3): 237-248.

Pollard, R. 2002. "Evidence of a reduced home advantage when a team moves to a new stadium." Journal of Sports Sciences, 20(12): 969-973.

Ponzo, M., and V. Scoppa. 2018. "Does the Home Advantage Depend on Crowd Support? Evidence From Same-Stadium Derbies.” Journal of Sports Economics, 19(4): 562-582.

Rocha, B., F. Sanches, I. Souza, and J. C. D. da Silva. 2013. "Does monitoring affect corruption? Career concerns and home bias in football refereeing." Applied Economics Letters, 20(8): 728-731.

Rottenberg, S. 1956. “The baseball players' labor market.” Journal of Political Economy, 64(3): 242-258.

Sacheti, A., I. Gregory-Smith, and D. Paton. 2015. "Home bias in officiating: evidence from international cricket.” Journal of the Royal Statistical Society: Series A (Statistics in Society), 178(3): 741-755.

Schreyer, D., S. L. Schmidt, and B. Torgler. 2018a. "Game outcome uncertainty and television audience demand: New evidence from german football.” German Economic Review, 19(2): 140-161.

Schreyer, D., S. L. Schmidt, and B. Torgler. 2018b. "Game Outcome Uncertainty in the English Premier League: Do German Fans Care?” Journal of Sports Economics, 19(5): 625-644.

Schwartz, B., and S. Barsky. 1977. “The home advantage.” Social Forces, 55(3): 641-661.

Scoppa, V. 2008. "Are subjective evaluations biased by social factors or connections? An econometric analysis of soccer referee decisions." Empirical Economics, 35(1): 123-140.

Stoecker, C., N. J. Sanders, and A. Barreca. 2016. "Success Is something to sneeze at: Influenza mortality in cities that participate in the Super Bowl." American Journal of Health Economics, 2(1): 125-143.

Sutter, M., and M. Kocher. 2004. "Favoritism of agents - The case of referees' home bias." Journal of Economic Psychology, 25(4): 461-469.

Wilkinson, T., and R. Pollard. 2006. "A Temporary Decline in Home Advantage When Moving to a New Stadium.” Journal of Sport Behavior, 29(2): 190-197.

Wolfson, S., D. Wakelin, and M. Lewis. 2005. "Football supporters' perceptions of their role in the home advantage." Journal of Sports Sciences, 23(4): 365-374.

Wooldridge, J. M. 2010. Econometric Analysis of Cross Section and Panel Data. MIT press. 